\title{
Amniotic air insufflation during minimally invasive fetoscopic fetal cardiac interventions is safe for the fetal brain in sheep
}

Thomas Kohl, MD, a,b Julia Reckers, MD, ${ }^{\mathrm{b}}$ Danja Strümper, MD, ${ }^{\mathrm{c}}$ Maike Große Hartlage, $\mathrm{MD}^{\mathrm{c}}$ Wiebke Gogarten, $\mathrm{MD},{ }^{\mathrm{c}}$ Ulrich Gembruch, MD, ${ }^{\mathrm{a}}$ Johannes Vogt, MD, ${ }^{\mathrm{b}}$ Hugo Van Aken, MD, ${ }^{\mathrm{c}}$ Hans H. Scheld, MD, ${ }^{\mathrm{d}}$ Werner Paulus, MD, ${ }^{\mathrm{e}}$ and Christian H. Rickert, MD ${ }^{\mathrm{e}, \mathrm{f}}$

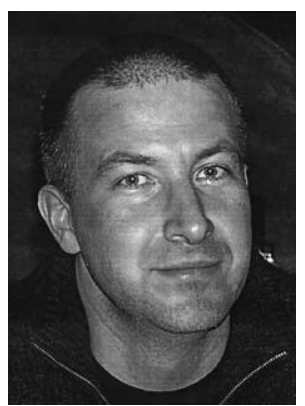

Dr Kohl

From the Division of Obstetrics \& Prenatal Medicine, University Hospital of Bonn, Bonn, Germany, ${ }^{a}$ Department of Pediatric Cardiology, Münster University Children's Hospital, Münster, Germany, ${ }^{\text {b }}$ and Department of Anesthesiology \& Perioperative Intensive Care, ${ }^{\mathrm{c}}$ Department of Thoracic \& Cardiovascular Surgery, ${ }^{\mathrm{d}}$ Institute of Neuropathology, ${ }^{e}$ and Institute of Pathology, ${ }^{f}$ Münster University Hospital, Münster, Germany.

Supported by a research grant (Ko 1484/ 3-2) from the German Research Society, Bonn, Germany (T.K.).

Received for publication Nov 24, 2003; revisions requested Dec 30, 2003; revisions received Jan 12, 2004; accepted for publication Jan 28, 2004

Address for reprints: Thomas Kohl, MD, German Center for Fetal Surgery, Department of Obstetrics \& Prenatal Medicine, University of Bonn Medical School, 53105 Bonn, Germany (E-mail: thokohl@t-online. de).

J Thorac Cardiovasc Surg 2004;128:467-71 0022-5223/\$30.00

Copyright (C) 2004 by The American Association for Thoracic Surgery

doi:10.1016/j.jtcvs.2004.01.012
Background: Amniotic air insufflation during experimental fetoscopic fetal cardiac interventions greatly improves the visualization of intra-amniotic contents. The purpose of this study was to assess any histologically discernible effects from this approach on the fetal brain after short-term studies and long-term survival in sheep.

Methods: Thirty pregnant ewes between 80 and 110 days of gestation underwent amniotic air insufflation during various fetoscopic fetal cardiac interventions. After 18 short-term and 12 long-term studies, the brains of the operated fetuses and-if available - their unoperated siblings were examined for hemorrhage, embolism, infarctions, inflammatory changes, and abnormal cortical maturation.

Results: Amniotic air insufflation during minimally invasive fetoscopic fetal cardiac interventions did not result in any histologically discernible damage to the brain in short-term and long-term studies in any but 2 sibling sheep. In the 2 affected siblings, a small area of chronic cortical frontal lobe infarction was observed after long-term survival.

Conclusions: Amniotic air insufflation during minimally invasive percutaneous fetoscopic fetal cardiac interventions is safe for the fetal brain and does not compromise maternal hemodynamics in sheep. These findings encourage further investigation of the role this technique might play during fetoscopic fetal cardiac interventions in humans.

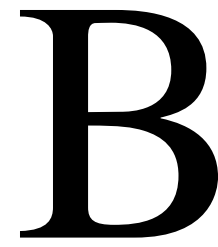

rain injury has been observed after open fetal surgery in human fetuses with noncardiac lesions and may be the result of hemodynamic disturbances induced by the unphysiologic stress of the open operative approach. ${ }^{1,2}$ Supporting this concept, critical decreases in fetoplacental and uterine blood flows have been observed after open fetal surgery in both human fetuses and animals. ${ }^{3,4}$ These hemodynamic changes may be particularly detrimental to fetuses already compromised by cardiac disease.

As a less invasive alternative to the open operative approach, fetoscopic fetal cardiac interventions have been developed in sheep and await clinical introduction in highly selected human fetuses with severe semilunar valve obstructions and therapy-refractory arrhythmias. ${ }^{5-10}$ Early clinical experience in human fetuses undergoing fetoscopic procedures for noncardiac lesions and results of animal studies 
provide evidence that fetoplacental and uterine blood flows remain unaffected during these far less invasive operative procedures. ${ }^{3,11-13}$

These important hemodynamic advantages of the fetoscopic approach are bought at the price of increased procedure time and technical restraints. The poorly illuminated and confined 2-dimensional video field of small fetoscopes significantly impairs visualization and orientation during the operation. ${ }^{8}$ Although visualization of the surgical region of interest may be improved by continuous exchange of amniotic fluid with crystalline solutions, the fluid volumes that can be exchanged via the small-caliber fetoscopic instrumentation may not suffice if intra-amniotic bleeding occurs. Particularly during interventions that require direct fetal cardiac or vascular access, adequate visualization may be maintained only by partial evacuation of amniotic fluid followed by amniotic gas insufflation. ${ }^{7}$ Because data regarding the safety of amniotic gas insufflation during fetoscopic fetal cardiac interventions for the fetal brain were not available, the purpose of this study was to assess any histologically discernible effects from this approach on this organ after short-term studies and after long-term survival in sheep. Of even greater importance, we monitored for any deleterious cardiovascular effects of amniotic air insufflation in the ewe.

\section{Methods}

The studies were performed in 30 time-bred fetal sheep. Age at operation ranged between 80 and 110 days of gestation (median, 90 days; term, 145-150 days). Each ewe was positioned supine with a $15^{\circ}$ left tilt, intubated, and ventilated with $0.5 \%$ to $2 \%$ halothane in $50 \%$ oxygen. Placental transfer of the anesthetic gas provided fetal anesthesia.

Fetal access was achieved via 3 to 4 trocars that were percutaneously inserted into the amniotic cavity. Whereas the first trocar was placed under ultrasound guidance, subsequent trocars were placed under fetoscopic guidance. After partial amniotic fluid evacuation, the amniotic cavity was insufflated with compressed air. Insufflation pressures ranged from 8 to $14 \mathrm{~mm} \mathrm{Hg}$. Various percutaneous fetoscopic cardiac procedures were performed, including fetal transesophageal electrocardiography and overdrive stimulation, fetal sternotomy and pacing lead insertion, fetal sternotomy, and antegrade fetal cardiac catheterization, as well as transumbilical fetal cardiac catheterization.

During the operations, maternal electrocardiogram, blood pressure, and end-expiratory carbon dioxide concentration were continuously monitored for detrimental cardiovascular effects on the ewe from amniotic insufflation, which ranged from 2.5 to 4.5 hours (mean, 3 hours). The study protocols were approved by the local committee on animal research and were performed according to institutional and government guidelines for the provision of humane care to laboratory animals.

\section{Short-Term Studies}

Eighteen anesthetized pregnant ewes (92-109 days of gestation; term, 145 days) were killed under general anesthesia by intravenous administration of an overdose of potassium chloride immediately after completion of the intervention. A total of 30 fetal brains were available from these consecutive short-term studies, 12 of which came from unoperated siblings and served as controls. Four of the operated fetuses had been heparinized with $200 \mathrm{U} / \mathrm{kg}$ estimated fetal weight to avoid clot formation from intracardiac manipulations with guidewires and balloon catheters during experimental fetal cardiac catheterization.

\section{Long-Term Studies}

Twelve ewes and their fetuses continued gestation after fetal cardiac pacing lead insertion $(\mathrm{n}=8)$ or fetal cardiac catheterization $(n=4)$ between 80 and 110 days of gestation (term, 145 days). At term, 10 of the 12 operated fetuses as well as 9 unoperated siblings were delivered and available for study. As in the short-term procedures, the 4 fetuses that underwent fetal cardiac catheterization had been heparinized with $200 \mathrm{U} / \mathrm{kg}$ estimated fetal weight.

After delivery, the 19 newborn sheep were examined for clinically evident neurologic deficits presenting as movement disorders or the inability to establish a normal feeding pattern. Two of the 12 operated fetuses died early after the procedure, yet the ewes continued gestation. At term, live twin and triplet siblings were delivered and available for the histologic studies. Unfortunately, the 2 stillborn fetuses were too mummified to be studied. In addition, we examined the brain of 1 newborn sheep that was delivered severely malnourished at 142 days of gestation and that died in the first hours of life. Apart from being too small for gestational age (birth weight, $1800 \mathrm{~g}$ ), no organ anomalies were observed in this animal. At operation at 94 days of gestation, the fetus had been found entirely wrapped by amniotic membrane, which was widely excised to perform the procedure. This fetus had a normally sized sibling that was electively killed 3 weeks after birth and was also included in this study.

Similar to the research animals in the short-term study arm, all ewes and lambs of the long-term study arm were killed after ketamine premedication and induction of general anesthesia by intravenous administration of an overdose of potassium chloride.

\section{Histologic Preparations}

Immediately after their termination, the fetuses or lambs were perfusion-fixed with $4 \%$ buffered formaldehyde, and their brains were removed. After submersion of the brains in $4 \%$ buffered formaldehyde over at least 2 weeks, sectioning and mounting was followed by staining with hematoxylin-eosin, Klüver-Barrera Luxol fast blue (Chromo, Köngen, Germany), and van Gieson stains. In addition, immunohistochemical staining was performed with the macrophage/microglial marker KiM1P (CD68), the leukocyte common antigen CD45, and the glial fibrillary acidic protein (GFAP) antigen. All brains were examined for bleeding complications, infarctions, embolic events, and acute inflammatory tissue reactions or abnormal cortical migration and maturation. 


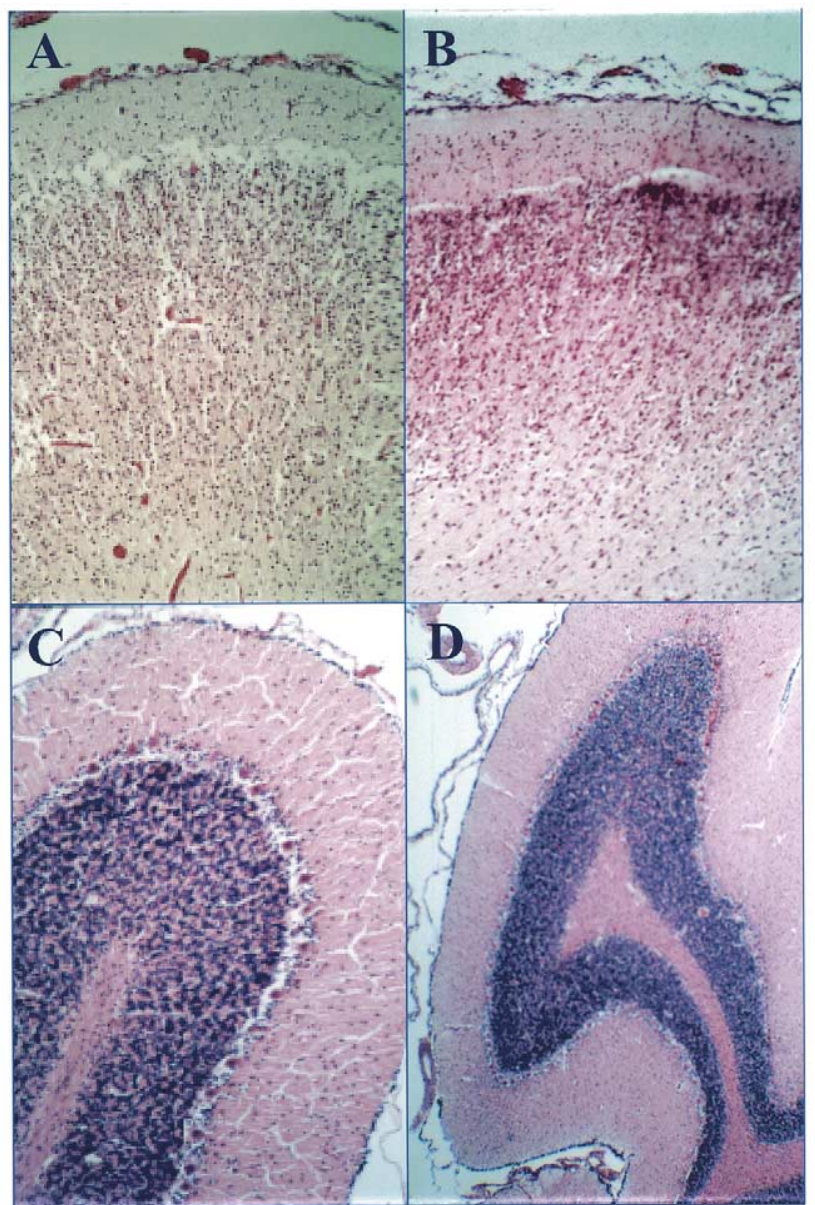

Figure 1. Fetal sheep cortex in an operated sheep (A) and an unoperated sibling (B) (stain, hematoxylin-eosin; magnification, $12 \times)$. The operated sheep and unoperated control exhibited normal histology without pathologic findings. Fetal sheep cerebellum is shown in an operated sheep (C) and an unoperated sibling (D) (stain, hematoxylin-eosin; magnification, $24 \times$ ). The operated sheep and unoperated control exhibited normal histology without pathologic findings. Likewise, no other staining revealed any pathology.

The pathologist (C.H.R.) was blinded to which of the fetuses or lambs had undergone an operation or had been delivered as an unoperated sibling.

\section{Results}

\section{Maternal Effects of Amniotic Insufflation}

Amniotic air insufflation during fetoscopic fetal cardiac interventions did not result in any detrimental cardiovascular effects in the ewe, as assessed by arterial blood gas analyses, continuous maternal electrocardiogram, blood pressure, and end-expiratory carbon dioxide concentration monitoring.

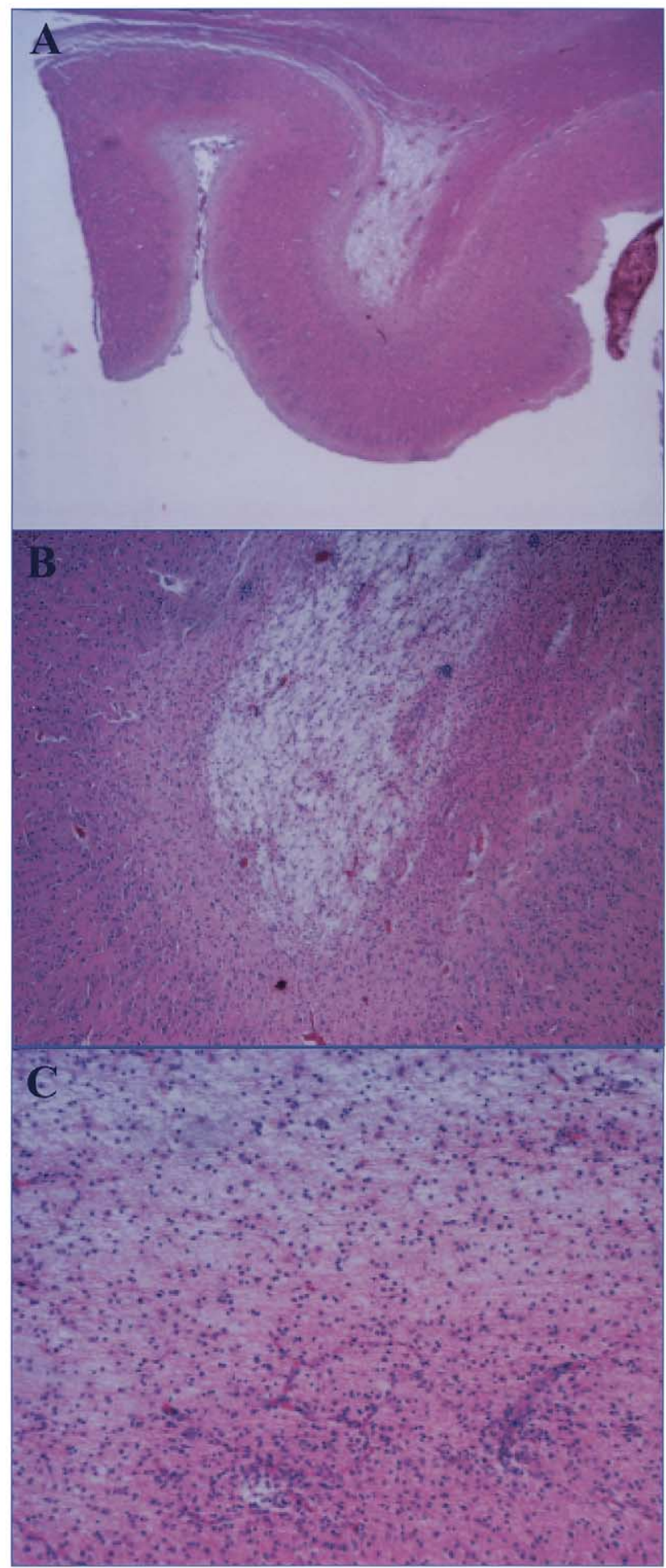

Figure 2. Fetal sheep cortex in the only operated sheep that demonstrated pathologic findings. A, Old white matter necrosis (ischemic infarction) with an intact cortical ribbon (stain, hematoxylin-eosin; magnification, $12.5 \times$ ). B, White matter necrosis with Iymphoplasmacellular infiltrates at the edges of the lesion (stain, hematoxylin-eosin; magnification, $40 \times$ ). C, Lymphoplasmacellular infiltrates and proliferating capillaries at the edge of the necrosis (stain, hematoxylin-eosin; magnification, $200 \times$ ). 


\section{Short-Term Studies}

In all 18 operated sheep and their 12 unoperated siblings, minimally invasive fetoscopic fetal cardiac interventions did not result in any changes to the fetal brain that were discernible by the various staining methods.

\section{Long-Term Studies}

In the entire long-term study group, intraventricular or parenchymal hemorrhage, embolic events, acute inflammatory tissue reactions, and abnormalities of cortical maturation were not observed after the fetoscopic fetal cardiac interventions (Figure 1). In one of the prenatally operated lambs and its unoperated sibling, a small volume (diameter of approximately $5 \mathrm{~mm}$ ) of cortical frontal lobe infarction was observed (Figure 2). Despite these changes, these 2 newborn lambs and all other long-term study lambs seemed entirely neurologically normal after delivery; they exhibited typical movement and feeding patterns and interacted normally.

\section{Discussion}

Our study shows that amniotic air insufflation is safe for the fetal brain in sheep and does not compromise hemodynamics in the ewe. These findings encourage further investigation of the role this technique might play in improving visualization during minimally invasive fetoscopic fetal cardiac interventions in humans.

Although we examined various brain regions that are particularly sensitive to vascular or hypoxic injury, we found no histologically discernible damage in any but 2 sibling sheep. Each of these 2 fetuses had a small infarcted area in a similar location inside the frontal lobe, although the unoperated sibling lay in a different sac that remained filled with amniotic fluid and was untouched throughout the operation. Given this constellation, it seems unlikely that amniotic insufflation contributed to these lesions. However, because this injury might have also occurred as a result of the intervention, a small but definite risk for cerebral injury and death associated with amniotic gas insufflation during fetoscopic fetal cardiac interventions may exist.

We chose compressed air as the amniotic insufflation medium during our operations because of its low potential for biologic interaction and because it permits the use of electrocautery or laser energy with a negligible risk of combustion. ${ }^{7}$ For the same reasons, other investigators have used helium or nitrous oxide during their studies in sheep. $^{14,15}$ The disadvantage of any of these gases (air, helium, or nitrous oxide) is that they progressively accumulate inside the maternal peritoneal cavity by leaking along the trocar shafts. ${ }^{7}$ Therefore, venting maneuvers are required to maintain the operative setup. Although amniotic insufflation with carbon dioxide offers an alternative because it is quickly absorbed from the maternal peritoneal cavity, we have favored the use of air because carbon dioxide insufflation may result in fetal acidosis in sheep. ${ }^{14,16,17}$ In this setting, the efficacy of maternal hyperventilation for ameliorating fetal hypercarbic acidosis during amniotic carbon dioxide insufflation in sheep has been debated. ${ }^{17,18}$

There were several study limitations. Air insufflation of the peritoneal cavity has been safe in thousands of patients. ${ }^{19}$ In contrast, the potential for serious maternal or fetal complications during insufflation of the amniotic cavity with air or other gases in humans is not known. Although maternal gas or amniotic fluid embolism was not observed when placental abruption occurred during an attempt of fetoscopic repair of spina bifida by using amniotic insufflation with carbon dioxide, ${ }^{20}$ it is conceivable that in the presence of high insufflation pressures and placental injury, intra-amniotic gas or fluid might enter the maternal or fetal circulation. Because of the marked differences in placental anatomy between sheep and humans, additional studies are necessary to establish the margins of safety and to define the most suitable insufflation gas for amniotic insufflation in humans.

We thank Sybill Storz (Karl Storz GmbH, Tuttlingen, Germany), who provided all of the fetoscopic equipment for our studies; Medtronic Bakken Research Center (Maastricht, The Netherlands); Stefan Brodner, for expert technical assistance; W. L. Gore Inc (Putzbrunn, Germany) and Ethicon (Norderstedt, Germany), for providing suture material; Ross Product Division, Abbot Laboratories (Columbus, Ohio), for providing T-fasteners; Erbe Elektromedizin (Castrop-Rauxel, Germany), for providing a radiofrequency system for our studies; and Allegiance Healthcare (Kleve, Germany) and Mölnlycke Health Care (Göteburg, Sweden), for providing surgical gowns and drapings for our study.

\section{References}

1. Bealer JF, Raisanen J, Skarsgard ED, Long SR, Wong K, Filly RA, et al. The incidence and spectrum of neurological injury after open fetal surgery. J Pediatr Surg. 1995;30:1150-4.

2. Flake AW, Crombleholme TM, Johnson MP, Howell LJ, Adzick NS. Treatment of severe congenital diaphragmatic hernia by fetal tracheal occlusion: clinical experience with fifteen cases. Am J Obstet Gynecol. 2000;183:1059-66.

3. Luks FI, Peers KH, Deprest JA, Lerut TE, Vandenberghe K. The effect of open and endoscopic fetal surgery on uteroplacental oxygen delivery in the sheep. J Pediatr Surg. 1996;31:310-4.

4. Kohl T, McElhinney DB, Farrel J, Scheld HH, Vogt J, Harrison MR, et al. Impact of fetoscopic versus open fetal surgery on fetoplacental blood flow and outcome in human fetuses [abstract]. Eur Heart J. 1999;20(suppl):644A.

5. Kohl T, Szabo Z, Suda K, Petrosian E, Ko E, Kececioglu D, et al. Fetoscopic and open transumbilical fetal cardiac catheterization in sheep-potential approaches for human fetal cardiac intervention. Circulation. 1997;95:1048-53.

6. Kohl T, Kirchhof P, Gogarten W, Asfour B, Haverkamp W, Reckers $\mathrm{J}$, et al. Fetal transesophageal electrocardiography and stimulation in sheep-fetoscopic techniques aimed at diagnosis and therapy of incessant fetal tachycardias. Circulation. 1999;100:772-6.

7. Kohl T, Witteler R, Strümper D, Gogarten W, Asfour B, Reckers J, et al. Operative techniques and strategies for minimally invasive fetoscopic fetal cardiac interventions in sheep. Surg Endosc. 2000;14:424-30. 
8. Kohl T, Strümper D, Witteler R, Merschhoff G, Aleksiene R, Callenbeck $\mathrm{C}$, et al. Fetoscopic direct fetal cardiac access in sheep-an important experimental milestone along the route to human fetal cardiac intervention. Circulation. 2000;102:1602-4.

9. Kohl T, Westphal M, Strümper D, Achenbach S, Halimeh S, Petry P, et al. Multimodal fetal transesophageal echocardiography for fetal cardiac intervention in sheep. Circulation. 2001;114:1757-60.

10. Kohl T, Große Hartlage M, Westphal M, Kienitz D, Aryee S, Achenbach $\mathrm{S}$, et al. Intraamniotic multimodal fetal echocardiography in sheep - a novel imaging approach during fetoscopic interventions and for assessment of high-risk pregnancies in whom conventional imaging methods fail. Ultrasound Med Biol. 2002;28:731-6.

11. Kohl T, McElhinney DB, Farrel J, Scheld HH, Vogt J, Harrison MR, et al. Impact of fetoscopic versus open fetal surgery on fetoplacental blood flow and outcome in human fetuses [abstract]. Eur Heart J. 1999;20(suppl):644A.

12. van der Wildt B, Luks FI, Steegers EA, Deprest JA, Peers KH Absence of electrical uterine activity after endoscopic access for fetal surgery in the rhesus monkey [letter]. Eur J Obstet Gynecol Reprod Biol. 1995;58:213-4.

13. Harrison MR, Mychaliska GB, Albanese CT, Jennings RW, Farrell JA, Hawgood S, et al. Correction of congenital diaphragmatic hernia in utero IX: fetuses with poor prognosis (liver herniation and low lungto-head ratio) can be saved by fetoscopic temporary tracheal occlusion. J Pediatr Surg. 1998;33:1017-22; discussion 22-3.
14. Pelletier GJ, Srinathan SK, Langer JC. Effects of intraamniotic helium, carbon dioxide, and water on fetal lambs. J Pediatr Surg. 1995;30: 1155-8.

15. Gratacos E, Wu J, Devlieger R, Bonati F, Lerut T, Vanamo K, et al. Nitrous oxide amniodistention compared with fluid amniodistention reduces operation time while inducing no changes in fetal acid-base status in a sheep model for endoscopic fetal surgery. Am J Obstet Gynecol. 2002;186:538-43.

16. Luks FI, Deprest JA, Marcus M, Vandenberghe K, Vertommen JD, Lerut T, et al. Carbon dioxide pneumoamnios causes acidosis in fetal lambs. Fetal Diagn Ther. 1994;9:105-9.

17. Gratacos E, Wu J, Devlieger R, Van de Velde M, Deprest JA. Effects of amniodistension with carbon dioxide on fetal acid-base status during fetoscopic surgery in the sheep model. Surg Endosc. 2001;15:36872.

18. Sayki Y, Litwin DE, Bigras JL, Waddel J, Konig A, Baik S, et al. Reducing the deleterious effects of intrauterine $\mathrm{CO}_{2}$ during fetoscopic surgery. J Surg Res. 1997;69:51-4.

19. Diaz MO, Atwood RJ, Laufe LE. Laparoscopic sterilization with room air insufflation: preliminary report. Int J Gynaecol Obstet. 1980;18: 119-22.

20. Bruner JP, Richards WO, Tulipan NB, Arney TL. Endoscopic coverage of fetal myelomeningocele in utero. Am J Obstet Gynecol. 1999; 180:153-8 (1 Pt 1). 